\title{
Review of collusion and bid rigging detection methods in the construction industry
}

\author{
Andrzej Foremny ${ }^{\mathrm{a}}$ \\ Wojciech Dorabialski ${ }^{\mathrm{b}}$ \\ ${ }^{a}$ Warsaw University of Technology, Plac Politechniki 1, Warsaw 00-661, Poland \\ ${ }^{b}$ Office of Competition and Consumer Protection, Plac Powstańców Warszawy 1, Warsaw 00-950, Poland
}

\begin{abstract}
Collusion and bid rigging are deplorable practices, forbidden by law. They are harmful to the society and dangerous for a free market economy. Due to the high value of construction industry production and the importance of the time factor, anti-competitive behaviour in that sector can result in losses extremely significant for the national economy. Effective elimination of cartels and bid rigging requires detection, prosecution and successful penalization of cartels. Disrupting already existing cartels and deterring new ones from emerging is efficient only when there is an effective cooperation between the three above mentioned stages. Classification and brief description of numerous existing collusion and bid rigging methods were performed in this paper. As a conclusion, the author presents an idea to combine AI (Artificial Intelligence) and BIM (Building Information Modeling) together as useful tools for early detection of collusion and bid rigging in public tenders.
\end{abstract}

(C) 2018 The Authors. Published by Diamond Congress Ltd., Budapest University of Technology and Economics Peer-review under responsibility of the scientific committee of the Creative Construction Conference 2018.

Keywords: artificial intelligence, artificial neural networks, bid rigging, BIM, collusion, fuzzy logic

\section{Main text}

Bid rigging and other anti-competitive agreements are not easily observed by other market participants. Moreover, building entrepreneurs are usually aware that such practices are illegal and it is necessary for them to remain undetected. This is the reason for why the fight against anti-competitive agreements led by public services requires particular measures, especially swift exposure and effective evidence collection [1]. Hiding evidence of economic activity or refusing to cooperate with competition authorities occurs also in other types of investigation. However, only in case of anti-competitive agreements, such actions constitute a fundamental obstacle to overcome which may affect the efficiency of public services. Even the most experienced and well-equipped public services are not characterised by high efficiency of cartel detection. Measuring the efficiency of cartel detection is as difficult as detection itself; irrespective of the implemented method, economist estimate the upper limit of efficiency index for 10-20\% [2]. In order to improve detection statistics, the research on enhancing the effectiveness of anti-competitive agreement detection tools and creating new ones is being conducted nowadays. They can be efficient if they are an integral part of the entire cartel detection system, consisting of such elements as violation detection, promotion of competition, tools of active evidence collection (e.g. search warrants or wiretapping) and the policy of preventive punishment. In the recent years, rapid IT development took place, which enabled the collection, storage and processing of huge amounts of data also in the construction industry. On the other hand, previously inconceivable manners of anticompetitive agreements arose simultaneously [3]. Enormous databases provide the possibility to observe technico- 
economic phenomena. However, considering these large amounts of data, its exploration with the previously used tools became problematic. In such cases, artificial intelligence techniques such as neural networks or fuzzy modelling, proved to be useful. Implementing artificial intelligence into construction industry might allow for detection of abnormalities, classification of phenomena (i.a. anti-competitive agreements) [4,5] or prediction of delays [6,7]. In this paper, the author provided an overview of the existing methods of anti-competitive agreement detection. An innovative idea concerning bid rigging detection in the construction industry is presented in this paper; it may utilize an electronic procurement platform, BIM and artificial intelligence methods (neural networks, fuzzy modelling and data mining).

\section{Methods of anti-competitive agreement detection}

\subsection{Econometric and statistical methods}

Econometric methods were implemented by Porter and Zona [8] in order to analyse the market for milk sold to schools in the State of Ohio, USA [8]. They performed various tests which enabled them to assess what factors influence the decision whether to submit a tender and at what price. Considering that the analysis was being undertaken already after the detection of an anti-competitive agreement, behaviour of each tenderer was being compared to the reference group, comprised of entrepreneurs not participating in the collusion. The behaviour of collusion participants varied significantly from the behaviour observed in the reference group. The greater likelihood to submit an offer for tenders launched by the most closely located recipients was one of the relevant discriminants among relevant indicators of their behaviour (which is consistent with the market partitioning mechanism). The cartelists submitted offers for tenders, during which also other cartelists were present, more often than it would logically follow from the competitive business model (consistent with the fake tender offer mechanism). What is interesting, the values of offers submitted by the collusion members varied accordingly to the consignees' location. The closer the location, the higher was the offer. Such practices are inconsistent with the competitive model, according to which transportation costs should cause an increase of offered prices proportionately to the increase of distance.

The same authors performed an ex post examination using another method to analyse the changes in behaviour of a certain cartel. It operated in the 1980s, on the public road construction market in Long Island, New York [9]. Almost always more than just one collusion member participated in rigged tenders. Evidence shows that the fake tender offer mechanism was being exploited. The authors examined whether there are statistically relevant connections between offers from the cartelists' group and the reference group. A simple test showed, that the „rigged” offers were less dispersed that the competitive offers (smaller difference between the two lowest priced offers). The estimates of the probability of submitting a winning offer in case of each company in respective tenders allowed for the application of a test for the distribution of the offers' order. The actual distribution of offers was consistent with the theoretical one (resulting from the estimated pattern) for the group of non-cartelists. The cartelists' behaviour significantly differed from the behavioural model. Their offers were less strictly connected with the measures of service costs than the offers of entrepreneurs not participating in the collusion. Other examples of research on bid rigging detection in the road construction industry are the works of Gabrielli [10], Podkolzina [11] and Padhi [12].

Bajari and Ye created a method of testing the behaviour of the collusion members with regard to the autonomy of submitted offers [13]. It was proved that bid functions must meet two conditions in the competitive balance: conditional independence and exchangeability. The first condition requires that offers of independent entrepreneurs should not be correlated with each other after the analysis of all individually observed cost factors. Exchangeability means that the generic offer distribution remains the same after entrepreneurs have exchanged individual cost factors. Even if there are colluding parties in a given tender, the condition of conditional independence and exchangeability will be satisfied by the participants not involved in the collusion. Thus, the Bajari and Ye's method may allow for factual identification of the cartel members as opposed to the test of Porter and Zona which is difficult to apply without the preceding hypothesis on the cartel's composition.

Marshall and Marx examined the operational schemes of a cartel and defined a super-plus factor of a cartel's existence [14]: "A reliable, econometric prediction model which takes into account the influence of all external factors relevant for the price, estimated from comparative data concerning non-coordinated behaviour and predicts the prices inconsistent with a factual price path during the time or at the place of collusions, on an assumed level of confidence". Such a model is being used more often for the estimation of overcharge in cases of private lawsuits [15]. In terms of cartel detection, the goal is not to calculate the overcharge paid by contractors, but to check whether the prices were being overstated. Descriptions of such model types can be found in the Oxera report [16] for the European Commission and in the following document of the Commission [17]. The key to efficiency is to establish an appropriate benchmark 
(most likely the period of time free of any collusion), to construct a model and to prepare any data allowing for the consideration of all relevant factors influencing the price formation in the competitive balance.

The analysis ordered by the British Office of Fair Trading [18] and performed by Grout and Sonderegger is a known example of an econometric method's application in detection of anti-competitive agreements. It was a screening test of 181 industrial sectors. The authors of this study estimated the level of influence of sectors' structural features (size of the market and its growth rate, cost of labour force, $\mathrm{R} \& \mathrm{D}$ expenses, concentration rates $\mathrm{C} 3$ and measures of the equity barriers for market entry) on cartel incidence in the given sectors. Due to the fact that cartel incidence is an unobservable variable, another one served as a response variable: the detection (or no detection) of a cartel in a given sector by the European Commission or in the United States in the years 1990-2004. The results of the logit model estimation were further used for the calculation of the probability of cartel occurrence in those sectors, where cartels had not been detected under the previously mentioned jurisdiction. Grout and Sonderegger's method can be summarized as identifying sectors similar (in terms of structural features) to those, in which cartels had been previously detected.

Authors of the report on corruption prepared for the European Commission used a comparable approach [19]. The report concerns the detection of abnormalities in public tenders, with horizontal bid riggings as the main group of abnormalities (48\% of analysed cases). The detection (or no detection) of abnormalities in a given tender constitutes a response variable. However, the authors highlighted that this particular variable is a good measure of factual occurrence of abnormalities, for the sample of tenders put under regression analysis was scrutinised in this regard. The estimation of a probit model was used by the authors to identify which of the chosen explanatory variables (e.g. the shortening of tender procedures, offerents' complaints/appeals, exceeding the estimated budget, unreliable filling of announcement forms, changes to the subject of a tender, tender values) are statistically relevant for the probability of abnormality occurrence. Statistically relevant variables were emphasised as red flags indicating possible abnormalities. The incidence rates of such selected indicators were used in the subsequent action to assess the risk of abnormalities occurrence, with a distinction into sectors and member countries.

\subsection{Indexing methods}

Harrington was also running research on the methods of cartel detection and bid rigging [20-23]. He established the set of indicators (regarding price behaviour and market shares) used for detecting cartels in screening tests. These indicators are connected to a structural gap in the prices and they may point towards the creation or dissolution of cartels [22]: increase of prices, accompanied by their unification; the period of permanent price increase, preceded by their sudden drop; increase of prices with a concurrent decrease of import rates; a strong correlation of prices between competitors; a great uniformity of prices and other parameters of a product or services; low price differentiation; less fluent price fluctuation; prices undergoing systematic changes; stability of the companies' market shares over time; negative correlation of a company's shares in the market (stock buybacks instead of trade wars).

Marshall and Max identified a slightly different set of indicators, dividing them into plus factors and super plus factors [14]. Some of them, especially super-plus factors, are quite complicated or require hardly available data, hence are not suitable for screenings. Although indexing methods do not require econometric modelling or statistical testing by the rule, they may employ certain statistical measures. However, such an approach does not disqualify formal statistical testing. The work of Bejger is an example of statistical inference used for detection of anti-competitive agreements. He applies statistical testing to i.a. assessment of the stability of the market shares belonging to the members of a cement cartel which existed in the years 1998-2006 in Poland [24].

Individual factors do not always guarantee low levels of type II errors. This is the reason for why screening programmes use multivariate methods of analysis more often [15]. The markets are being examined with regard to the occurrence of several indicators of anti-competitive collusions. In case of extensive research, e.g. Bid-Rigging Automated Analysis System created by The Korea Fair Trade Commission [25], such methods allow to rate tenders or bidders, as well as to create rankings of the risk of abuse, which increases the efficacy of successive actions of antitrust authorities. Another example of a multivariate method of analysis is Competition Index created by The Netherlands Competition Authority. It utilises 9 structural indexes (e.g. high level of market concentration, slow dynamics of demand, high level of participation in trade associations), which may facilitate the process of creation and existence of a cartel [26].

The weighting of indicators allows for creating an index which organises industry sectors according to the level of occurrence of anti-competitive agreements. It is worth mentioning that the methodology of index construction (especially weighting procedure is not entirely arbitrary, but it was verified through the comparison of indexing results 
with independent measures of competition in the industry sector (i.a. with an increase rate of the sector's productivity). A similar index (Aggregated Index of Competitive Pressure) has been established by the economists from the Romanian Competition Council [15].

Indexing methods originate from economic theories of oligopolistic coordination or are based on data regarding the activities of previously detected cartels. The expression of 'data mining' refers to a broad collection of the methods of irregularity detection or to the patterns in big data sets without an a priori assumption that there are existing theoretical or empirical basis for the occurrence of particular patterns. Data mining methods has been long applied for the detection of fraud and abuse in companies and they may be potentially used also for anti-competitive agreement detection, bid rigging in particular. As opposed to the indexing methods, such examination involves analysing data for the purpose of detecting some correlation or reliance and verifying whether observed patterns of behaviours are consistent with any other (previously known or new) collusion mechanisms. Therefore, they might help to detect the irregularities irrespective of information on the collusion members' identity or the mechanism of their cooperation. Data mining techniques may be complementary to the indexing methods or even serve as the foundation for the multivariate method creation. Such techniques are being used by i.a. the designers of the Bid Rigging Analysis System. Other techniques of fraud detection, such as tests for data manipulation, based on the Benford's law analysis, are also potentially fit for detection of anti-competitive agreements.

The usage of a multi-step algorithm may significantly improve the efficiency of anti-competitive agreement detection. Such an algorithm consists of running several consecutive tests, usually by the means of behavioural indicators, in order to successively narrow the groups of markets (tenders) or entrepreneurs suspected of the participation in a collusion [15]. A study carried out by Imhof et al. is an example of such an approach. They revealed the details of a procedure, which was performed during the tenders for construction contracts ordered by the Swiss cantonal authorities in 2004-2010 [27]. A five-step procedure was applied. In the first step, the number of dubious tenders was limited from 282 to 80 , based on the contestatory index developed for the need of this study. Secondly, the number of examined companies was narrowed to the most active 17. Next, the entrepreneurs were split into groups, inside which they might have potentially cooperated, based on their mutual interactions during the biddings. In the fourth step, the group composition was verified with regard to the geographic scope of their activity. Lastly, behaviour of given pairs of entrepreneurs was analysed and then presented on the graphs in order to compare their normalised price offers in these tenders, in which both parties participated. The application of this algorithm allowed for specifying several regions, where the entrepreneurs' behaviour resembled the mechanism observed in the previously detected collusion for road construction contracts in the canton of Ticino.

\section{Classification of anti-competitive agreement detection methods}

The division into reactive and proactive techniques constitutes the basic classification of methods detecting horizontal collusions. Reactive techniques include mostly passive waiting for the evidence of collusion. Opposed to them, proactive techniques consist of active searching for such evidence. The fundamental advantage of reactive methods is their simplicity and low cost. Proactive methods often require greater amounts of workload and analytical skills. Some of them are dependent on the access to particular data. The fact that they do not provide direct evidence of an anti-competitive agreement, but rather allow for retrieving indirect evidence, is an additional flaw of proactive methods. The least popular are individual sources of information, infiltration and other operational methods, as well as screening tests and econometric studies [15,20].

All above mentioned methods have the same goal. What is more, every one of them restricts the resources of antitrust authorities to a certain level. That is why some of the fair trade offices may see such methods as substitutable. It may lead to the decrease of their variety and to the selective application of only those most cost-efficient. Leniency programmes have recently become the most preferable method [21,28-30]. Their beginnings extend to the 1970s, when the first leniency programme was implemented in the USA. Nowadays, such programmes are present in the majority of the countries respecting antitrust law, including all OECD members. The efficacy of leniency programmes made some of the countries use them as the main method of cartel detection. The programmes resulted in so many requests for leniency that some antitrust bodies find other methods unnecessary, especially the costly proactive methods. The lack of proactive techniques of anti-competitive agreement detection causes members of the cartels already detected, unstable or at their end to submit requests for leniency, as these cartels are the most prone to seeking settlement. Thus, the leniency programme becomes a measure to acquire evidence solely against cartels at the end of their existence, and the preventive function of the programme is greatly restricted. The lack of proactive performance of the authorities makes it impossible to break up the cartel otherwise than from the inside, and it is not an efficient 
way in terms of a cartel steady for its members. Proactive methods pose a risk of a cartel detection from the outside, which may prevent another cartels from emerging. However, they do not provide any evidence of collusion. Reactive methods destabilise the existing cartels and are a source of direct evidence of collusion. Therefore, proactive and reactive methods should be seen as complementary and it ought to be tried to determine their appropriate proportions, considering the characteristics of a discussed market, legal system and the analytical abilities of antitrust bodies [15]. Intuition and knowledge of the actual functioning of the market are greatly important in the detection of anticompetitive agreements.

\subsection{Reactive methods}

Notification is a basic passive method of cartel and collusion detection. The notices may come from contractors or customers, who often identify the dubious behaviour of entrepreneurs quite adequately. What is more, other offices of public service (the prosecution, regulatory bodies) as well as other antitrust authorities can also submit notices. Notices originating from whistleblowers, thus insiders - former or current employees of the companies participating in collusions - are particularly valuable, for they usually include direct evidence of collusion. Reward schemes (for paid informants) and leniency programmes are the two most serious and grave reactive methods. The cement collusion on the Polish market can be shown as an example of leniency program application $[1,24]$.

\subsection{Proactive methods}

One of the simplest proactive techniques is the surveillance of publicly available data sources: the public media, the information supplied by economic intelligence or the news on interventions carried out by antitrust authorities in other jurisdictions. Another valuable source of intel on alleged problems in a given sector might be the analysis of complaints reported to an antitrust authority. A single report against an entrepreneur might not seem alarming but continuous complaints on the companies from the same sector might indicate the lack of effective competition, therefore also anticompetitive agreements. Market research may include retrieving and analysing data concerning a given sector. Although infiltration or other operational and economic methods seem efficient, they are being used quite rarely.

\subsubsection{Statistical predicative analysis and indexing methods}

To classify methods of illegal collusion detection, the first step is to divide them into categories based on the methodology of data processing. Statistical methods use econometric modelling or statistical inference in order to calculate the probability of the occurrence of an agreement impairing market competition. Indexing methods are called deterministic, focusing on individual signals or signal sets or on appropriate indexes allowing for the identification of the "dubious" markets. The superiority of statistical methods over indexing ones, claimed on the basis of the possibility of calculating the probability of market abuse, is mostly superficial. Firstly, statistical and econometric methods generate scores encumbered by many errors. Therefore, it is reasonable to treat the probability estimations with some doubt [15]. The main source of errors are differences in the functioning of a studied market and the markets of reference, in other words, the trouble of selecting an appropriate benchmark. Another market, the same market in a different period of time or other group of entrepreneurs (non-cartelists) operating in the same time as the market suspected of cartelization - all these may become markets of reference.

Another example of the source of error which may encumber the results of statistical methods are errors in the specification of a model or a statistical test, often caused by the restricted availability of data. Secondly, indexing methods often make use of statistical methods, e.g. the scores resulting from econometric studies might be utilized for the weighting of competition indexes. Moreover, such methods are based on economic theories and the information obtained from historic cartel cases. They also allow to establish the market classification with regard to the risk of illegal agreements' appearance which makes them extremely helpful tools for screening tests.

\subsubsection{Structural and behavioural methods}

The type of a symptoms examined in order to detect illegal collusion is another criterion of classification. There may be symptoms concerning the features of the discussed markets (structural methods) or the behaviour of entrepreneurs (behavioural method) [22,31]. Structural features may result from the company's behaviour or strategy to some extent, although they should derive from the sole nature of the market, namely, the character of the sector, its 
cost structure and demand. These are the features such as the level of market concentration, entry barriers (administrative, legal, R\&D expenses and advertisement) or the level of market concentration on the consumer's side, the stability of demand, customers' churn numbers or the frequency of new companies' market entrance [15].

Economic theories, the conditions of the stability of cartels (or tacit collusions) in particular, indicate the structural features of markets conducive to the establishment of collusion agreements and the formation and operation of cartels. Behavioural characteristics refer to the behaviour of respective entrepreneurs, mainly pricing strategy and individual shares in the market. In case of bid riggings, they refer to the more widely understood tender behaviour. Regarding such methods, economic theories, as well as conclusions arising from the study of the previously detected cartels, are the source of identification criteria for behavioural patterns which are consistent with the existence of an illegal agreement, or which are more suitable for the hypothesis of acting in liaison rather than the hypothesis of independent business decisions. The choice between the structural and the behavioural methods is being made based on available data, for general advantages and disadvantages of these methods are difficult to unequivocally appraise.

\subsubsection{Screening tests and in-depth research}

Another important differentiating factor is the scope of the markets included in a study, examined by one specified method. Methods that use basic and easily accessible data allow for running screens and the examination of many markets $[22,25,32]$. Such studies are encumbered by potentially big errors. However, like in medical research, they allow for a preliminary selection on markets exposed to collusion occurrence. A good screening method is characterized by a low level of type II errors (negative result in case of factual abuse) but a high level of type I error might be accepted (a positive result in case of detecting a non-existent abuse) [15].

In-depth studies are restricted only to selected markets. The used methods usually are not suitable for screening tests, because they are too labour-consuming or dedicated only to a specified sector. Depth of the study, which narrows the range of errors in collusion detection is an advantage of such techniques. However, if there are multiple markets in the screening test and there is no a priori suspicion or evidence of abuse, in-depth studies require already existing suspicions towards the market. The main problem with in-depth studies is the demand for more detailed data, usually unavailable for the public in-depth studies.

Performing an in-depth study carries a risk of pre-alarming the entrepreneurs suspected of participation in the collusion, which naturally impairs the evidence acquisition during e.g. a sweep. Therefore, antitrust authorities use indepth studies quite rarely, either only if high-quality data is publicly available (e.g. in case of regulated markets) or if there is no risk of pre-alarming the cartelists (e.g. the study's goal is to verify whether and when there was a neglect of a previously detected collusion). The ex post detection of cartels allows for development and evaluation of innovative methods used in the future.

\section{Summary}

Detecting anti-competitive agreements is difficult and requires vast interdisciplinary knowledge, experience, appropriate tool selection, availability of selected data, sometimes even a long term market observation [33]. The construction industry is particularly vulnerable for the occurrence of bid rigging (recurrent collusion) $([34,35])$ and other types of anti-competitive agreements because of the high values of contracts and the existing structure of oligopolistic market. Such practices may occur both in tenders for comprehensive construction work contracts and in the production of building materials or equipment performance alone.

In order to successfully combat cartels and bid rigging in the construction industry, it is necessary to constantly improve methods of their detection, follow technical progress and develop new tools, using the previously unavailable techniques and resources. One of the new methods for anti-competitive agreement detection might be a scheme of electronic tenders for public contracts in the construction industry (e-procurement). In such tenders, the ordering institution would use the Building Information Modelling model (build formula) as part of the announcement or it would post a functional-utility programme forming the basis for the execution of the BIM model presented to bidders (design and build formula). On an electronic platform, the antitrust authorities could store data concerning each tender thorough the years and on an unprecedented scale:

- Records of the tenderers and ordering institutions (administration, location, ownership structure, subcontracting);

- Records of tenders (price and other criteria, winners, appeals, consortium establishment);

- BIM models (individual prices, bill of quantities, applied technology and materials). 
Such a properly designed and systematically updated database might be analysed through the use of artificial intelligence with an objective to detect irregularities - relations indicating the possibility of collusion. The analysis of the discussed relations may be applied for the determination of simple rules historically present in the database of construction tenders. This type of analysis allows for monitoring the association rules usually hard to observe in a huge database by the use of conventional methods, such as stating that if specified conditions are met, there is a specified variable option. For instance, if a tender has fixed parameters (framework = "road works" and price > PLN 1 mln and work location = "masovian voivodeship"), the following rule is fulfilled: the winner is entrepreneurship A, B or C. The analysis of relations allows for the observation that some of the tenderers win only in specific geographical locations, although they participate in tenders also in other regions. In this situation, standard guidelines publicised by antitrust offices may prove useful [36-38]. Data mining could enable the retrieval of much valuable data from the offers of selected entrepreneurs and BIM models themselves.

Artificial Neural Networks might be used for classifying tenders into different risk groups of collusion occurrence at the stage of preliminary tender results. Such a solution would make it possible for regulatory offices to quickly determine a group which should be put under scrutiny and to assign appropriate operational resources for the purpose of more precise examination. The theory of fuzzy sets can be successfully used for the classification of road construction tenders following the criterion of the possibility of anti-competitive agreement occurrence, which is presented in paper [4].

However, it is the application of artificial intelligence as well as the BIM data with aim to integrate the processes of electronic tenders, that might be another milestone for efficient detection and substantiation of collusions in the construction industry. Techniques of artificial intelligence may effectively determine mutual relations, normally impossible to observe by conventional methods in the short period of time, for they make use of the great amounts of seemingly uncorrelated data. It could be, for instance, determining personal capital ties, geographical variability of ordered contracts, market concentration, materials applied in specified locations etc. The author is currently conducting further studies on the development of such a system.

\section{References}

[1] Office of Competition and Consumer Protection, Decision DOK-7/09 on price fixing and other portland cement sales conditions (2007) $1-17$.

[2] P.L. Ormosi, A tip of the iceberg? The probability of catching cartels, J. Appl. Econ. (2013).

[3] M. Stucke, A. Ezrachi, Artificial intelligence and collusion: when computers inhibit competition, Oxfort Cent. Compet. Law Policy. (2006) 1-11. doi:10.2139/ssrn.2591874.

[4] A. Foremny, H. Anysz, The collusion detection in public procurements - selected methods applied for the road construction industry in Poland, (2018). doi:10.13140/RG.2.2.16082.04807.

[5] H. Anysz, A. Foremny, J. Kulejewski, Estimating potential losses of the client in public procurement in case of collusion utilizing a MLP neural networks, Tech. Trans. 111 (2014) 105-118. doi:10.13140/2.1.2409.6321.

[6] H. Anysz, Usage of Artificial Neural Networks for assessment of the possibility of delay in the realisation of construction contracts, Warsaw University of Technology, 2018.

[7] H. Anysz, N. Ibadov, Neuro-fuzzy predictions of construction site completion dates, Czas. Tech. 6 (2017) 51-58. doi:10.4467/2353737XCT.17.086.6562.

[8] R.H. Porter, J.D. Zona, Ohio School Milk Markets : An Analysis of Bidding, RAND J. Econ. 30 (2017) $263-288$.

[9] R.H. Porter, J.D. Zona, Detection of Bid Rigging in Procurement Auctions, J. Polit. Econ. 101 (1993) 518-538. doi:10.1086/261885.

[10] M.F. Gabrielli, Detecting Collusion on Highway Procurement, Economica. LIX (2013) 1-31.

[11] I. Morozov, E. Podkolzina, Collusion Detection in Procurement Auctions, (2013). doi:10.2139/ssrn.2221809.

[12] S.S. Padhi, P.K.J. Mohapatra, Detection of collusion in government procurement auctions, J. Purch. Supply Manag. 17 (2011) 207221. doi:10.1016/j.pursup.2011.03.001.

[13] P. Bajari, L. Ye, Deciding between Competition and Collusion, Rev. Econ. Stat. 85 (2003) 971-989. doi:10.2307/3211820.

[14] R.C. Marshall, L.M. Marx, The Economics of Collusion, MIT Press. (2012).

[15] W. Dorabialski, Analitical methods of cartel and bid rigging detection, in: Conference materials from UOKiK and CARS Conference on Econ. of Competition Protection, 2015.

[16] Oxera, Quantifying Damages. Towards non-binding guidance for courts. Study Prepared for the European Commission, 2009. 
[17] Komisja Europejska, Practical Guide. Quantifying harm in actions for damages based on breaches of Article 101 or 102 of the treaty on the functioning of the European Union, 2013.

[18] P.A. Grout, S. Sonderegger, Predicting cartels, 2005.

[19] W. Wensink, J.M. de Vet, Identifying and Reducing Corruption in Public Procurement in the EU, (2013) 3-371.

[20] J.E. Harrington Jr., Detecting cartels, Handb. Antitrust Econ. (2008) 213-258.

[21] J.E. Harrington, M.-H. Chang, When Can We Expect a Corporate Leniency Program to Result in Fewer Cartels?, J. Law Econ. 58 (2015). doi:10.1086/684041.

[22] J.E. Harrington Jr., Behavioral screening and the detection of cartels, Eur. Compet. Law Annu. (2006).

http://citeseerx.ist.psu.edu/viewdoc/download?doi=10.1.1.63.4196\&rep=rep1 \&type $=$ pdf.

[23] J.E. Harrington, K. Hüschelrath, U. Laitenberger, F. Smuda, The discontent cartel member and cartel collapse: The case of the German cement cartel, Int. J. Ind. Organ. 42 (2015). doi:10.1016/j.ijindorg.2015.07.005.

[24] S. Bejger, Polish cement industry cartel - preliminary examination of collusion existence, Bus. Econ. Horizons. (2011) 88-107.

[25] Organisation for Economic Co-operation and Development (OECD), Ex Officio Cartel Investigations And The Use Of Screens to Detect Cartels, 2013. http://www.oecd.org/daf/competition/exofficio-cartel-investigation-2013.pdf.

[26] L. Petit, The Economic Detection Instrument of the Netherlands Competition Authority: The Competition Index, NMa Work. Pap. (2012). http://papers.ssrn.com/sol3/papers.cfm?abstract_id=1992774.

[27] D. Imhof, Y. Karagök, S. Rutz, Screening for bid-rigging - does it work?, 2014.

[28] C. Marvão, The EU Leniency Programme and Recidivism, Rev. Ind. Organ. 48 (2016). doi:10.1007/s11151-015-9474-z.

[29] J.R. Borrell, J.L. Jiménez, C. García, Evaluating antitrust leniency programs, J. Compet. Law Econ. 10 (2014). doi:10.1093/joclec/nht017.

[30] J. Sauvagnat, Are leniency programs too generous?, Econ. Lett. 123 (2014). doi:10.1016/j.econlet.2014.03.015.

[31] O. Bertrand, F. Lumineau, E. Fedorova, The Supportive Factors of Firms' Collusive Behavior: Empirical Evidence from Cartels in the European Union, Organ. Stud. 35 (2014) 881-908. doi:10.1177/0170840613515471.

[32] L.F. Roquete, Felipe L. V; Silva, Oecd. Latin American and Caribbean Competition Forum, Promot. Eff. Compet. Public Procure. (2016) 4.

[33] A. Foremny, J. Kulejewski, H. Anysz, A. Nicat, Collusion and bid rigging in the construction industry: case studies from Poland, (2018).

[34] A. Oke, C. Aigbavboa, Z. Mangena, Prevention of Collusion for Innovative Construction, Procedia Eng. 196 (2017) $491-497$. doi:10.1016/J.PROENG.2017.07.229.

[35] W.H. Boshoff, R. Van Jaarsveld, Recurrent collusion: Cartel episodes and overcharge in the South African cement market, (n.d.).

[36] Organisation for Economic Co-operation and Development (OECD), Fighting bid rigging in public procurement: Report on implementing the OECD Recommendation, 2016. http://www.oecd.org/competition/cartels/42594486.pdf.

[37] Organisation for Economic Co-operation and Development (OECD), OECD recommendation of the council on fighting bid rigging in public procurement, 2012.

[38] Office of Competition and Consumer Protection, Bid riggings, 2017. 